\title{
Epidemiology of the extent of recreational noise exposure and hearing protection use: cross-sectional survey in a nationally representative UK adult population sample
}

\author{
Christopher J. Armitage ${ }^{1,2^{*}}$ (D, Michael T. Loughran ${ }^{1,3}$ and Kevin J. Munro ${ }^{2,3}$
}

\begin{abstract}
Background: Hearing loss is prevalent and disabling, yet little is known about the extent of recreational noise exposure and hearing protection use. The aim of the present research was to estimate the extent of recreational noise exposure and hearing protection use in a sample representative of the UK adult population.

Methods: We conducted a cross-sectional survey of 10,401 UK adults who were representative of the population. Results: More than 7000 people $(n=7590,73.0 \%)$ reported exposure to recreational noise excluding headphone and earphone use in the last 12 months. Just 158 people (2.1\%) reported wearing hearing protection for every noisy recreational activity. Age (younger people) and beliefs of a behavioral (as opposed to genetic) cause of hearing loss were predictive of both higher recreational noise exposure and greater hearing protection use. Men were more exposed to recreational noise but women were less likely to use hearing protection.

Conclusions: For the first time, the present research quantifies the recreational noise exposure and low levels of hearing protection use in a representative sample of the UK population. The biggest public health gains are likely to be achieved through interventions targeted at younger people and in explaining behavioral (as opposed to genetic) causes of hearing loss.
\end{abstract}

Keywords: Hearing loss, Hearing protection, Prevalence

\section{Background}

Hearing loss is ranked 4th globally in years lived with a disability, with older age and noise exposure being the biggest risk factors [1]. Approximately one billion teenagers and young adults (12-35 years) are at risk of noise-induced hearing loss due to hazardous recreational listening behaviors [1]. These behaviors include attendance at live music venues (nightclubs, festivals, concerts

\footnotetext{
* Correspondence: chris.armitage@manchester.ac.uk

${ }^{1}$ Manchester Centre for Health Psychology, School of Health Sciences, University of Manchester, Manchester M13 9PL, UK

${ }^{2}$ Manchester University NHS Foundation Trust, Manchester Academic Health Science Centre, Manchester M13 9PL, UK

Full list of author information is available at the end of the article
}

and bars), practising/producing music, DIY, engine noise and sports related noise [2-6]. In many instances, the risks of recreational noise exposure can be reduced through the use of hearing protection devices (earplugs and earmuffs).

Numerous studies have tried to estimate recreational noise exposure and hearing protection uptake (e.g., use of earplugs and/or earmuffs), but have typically been limited to convenience [7-13] or regional samples [14-17] resulting in estimates of exposure and protection use ranging between 9 and 51\%, and 2-61\%, respectively. We were able to identify one study [18] that attempted to assess the prevalence of recreational noise exposure and use of

(C) The Author(s). 2020 Open Access This article is licensed under a Creative Commons Attribution 4.0 International License, which permits use, sharing, adaptation, distribution and reproduction in any medium or format, as long as you give appropriate credit to the original author(s) and the source, provide a link to the Creative Commons licence, and indicate if changes were made. The images or other third party material in this article are included in the article's Creative Commons licence, unless indicated otherwise in a credit line to the material. If material is not included in the article's Creative Commons licence and your intended use is not permitted by statutory regulation or exceeds the permitted use, you will need to obtain permission directly from the copyright holder. To view a copy of this licence, visit http://creativecommons.org/licenses/by/4.0/ The Creative Commons Public Domain Dedication waiver (http://creativecommons.org/publicdomain/zero/1.0/) applies to the data made available in this article, unless otherwise stated in a credit line to the data. 
hearing protection in a nationally representative sample of 18-35 year olds but their final sample included $76 \%$ women and was therefore not nationally representative, even ignoring the limited age range. Thus, little is known about the extent of recreational noise exposure and hearing protection use among the general population, beyond samples of adolescents and University students.

Without knowledge of the extent to which the general public are exposed to recreational noise and what is the prevalence of hearing protection device use, it will be difficult to develop interventions to reduce the health costs that might arise in the future nor what interventions might promote use of hearing protection. The aims of the present research are, for the first time in a representative sample of the UK adult population, to: (a) assess the extent of recreational noise exposure, and (b) assess hearing protection use.

Once the frequency of recreational noise exposure and prevalence of hearing protection use is established, the question then arises as to what are the correlates of exposure and use that will shed light on the kinds of populations and constructs that may be targeted/changed in future interventions. We therefore additionally examined potential correlates of recreational noise exposure and hearing protection use, in addition to sociodemographic variables and clinical characteristics (e.g., current hearing loss), we also considered beliefs about whether hearing loss is caused by genetics or health behaviors [19] to see whether public perceptions may need to be changed as well.

\section{Methods}

\section{Design}

The study design was cross-sectional and administered via an online survey.

\section{Participants}

A sample of adults designed to be representative of the UK adult (18+ years) population was invited by YouGov, a market research company, to take part in an online questionnaire in March 2019. YouGov has a panel of over one million potential respondents from whom they successfully recruited a sample of 10,401 UK residents, based on a $90.6 \%$ completion rate. Participants were incentivized in accordance with YouGov's points system, whereby respondents accumulate points for taking part in online surveys and the points can be traded for cash and gift cards. The data were sent securely to the research team for analysis. Ethical approval was obtained from a University of Manchester ethics committee (ref: 2019-5769-9246) and participants gave written informed consent by clicking on a series of boxes at the beginning of the online survey.

\section{Procedure}

A questionnaire, designed specifically for the purposes of the present study, was embedded in a wider online anonymous survey. We asked questions about participants' sociodemographic and clinical characteristics, recreational noise exposure, hearing protection use and beliefs about the causes of hearing loss. These questions are described briefly in the section below and are presented in the Additional file 1 . They include a mixture of standard items (e.g., sociodemographic characteristics) and standard items that were adapted for the present purposes (e.g., causal beliefs).

\section{Sociodemographic and clinical characteristics}

Sociodemographic measures of gender, ethnicity and socioeconomic status were taken using standard UK Office for National Statistics (2016) measures. Consistent with the ethnic profile of the UK, ethnicity was divided into White versus Black, Asian or Minority Ethnic. We gathered data on twelve occupational categories (see Additional file 1), but found no differences and so reported as manual versus non-manual. Participants were asked two questions derived from Benova et al. [20] to assess personal/familial experiences with hearing loss: "Do you have any difficulty with your hearing?" and "Do any of your family members currently have hearing loss?" to which participants were asked to respond "no" or "yes."

\section{Causal beliefs}

Participants' causal beliefs were assessed using measures adapted from Nguyen et al. [19] and were asked to respond to items regarding their beliefs about the roles of genetics and behavior in developing hearing loss. With respect to genetic causal beliefs, participants were asked, "How much do you think genetics, that is characteristics passed from one generation to the next, determine whether or not a person will develop hearing loss?"; behavioral causal beliefs were assessed with the question, "How much do you think health behaviors like diet, exercise and smoking determine whether or not a person will develop hearing loss?". Responses to both questions were given on identical four-point scales: not at all, a little, somewhat, and a lot.

\section{Extent of recreational noise exposure}

Participants were presented with a definition of "noisy leisure activities": A "noisy leisure activity" is where you need to raise your voice to be heard when at armslength from someone who has normal hearing. Do not include times when you are using headphones/earphones. Noisy activities can cover a wide range of settings such as: live music (e.g. concerts, festivals), nightlife (e.g. clubs, bars, pubs), making music (e.g. in a band, home producer), DIY (e.g. power tools, powered 
gardening tools), engine noise (e.g. motorbikes, motorboats, motorsports), sports related noise (e.g. watching rugby or football matches live, firearms and fireworks) or cinema." Following this, participants were asked, "How often did you take part in noisy leisure activities during the last 12 months?" [7, 15] to which they responded on an eight-point scale: "Almost every day," "5 or 6 times a week," "3 or 4 days a week," "Once or twice a week," "Once or twice a month," "Once every couple of months," "Once or twice a year," or "Not at all in last 12 months." Responses were coded such that higher values indicate greater exposure to noise during leisure activities.

\section{Hearing protection use}

Use of hearing protection during exposure to noisy leisure activities was measured using the item, "How often, if at all, do you use earplugs and/or earmuffs to protect your hearing when you take part in noisy leisure activities?" to which participants responded on an eleven-point scale from 0 to $100 \%$ that had $10 \%$ intervals, which was adapted for questionnaire use from Lutman et al. [21].

\section{Analyses}

Data were weighted to ensure analyses properly reflected the UK population. Descriptive statistics were used to characterize the population. Linear multiple regression was used to predict recreational noise exposure and logistic regression was used to identify predictors of hearing protection use.

\section{Results}

\section{Participant characteristics}

Consistent with the sampling frame, the sample was broadly representative of the UK population (Table 1 ). Most participants were white $(93.9 \%)$ and half were women (51.0\%) and roughly evenly split between people in non-manual (51.6\%) and manual occupations (48.4\%). Mean age was 47.41 years $(S D=1.48$; 18-93 years). Most people (75.9\%) did not report a hearing loss and did not have people in their family with hearing loss (67.4\%). Approximately half (49.8\%) of the sample believed that hearing loss was caused by genetics whereas just $16.8 \%$ thought that hearing loss had a behavioral cause.

Table 1 Characteristics of the Sample

\begin{tabular}{|c|c|c|c|}
\hline Variable & $\%$ & $M$ & $S D$ \\
\hline \multicolumn{4}{|l|}{ Gender } \\
\hline Men, $n=5007$ & 48.1 & - & - \\
\hline Women, $n=5305$ & 51.0 & - & - \\
\hline Age & - & 47.41 years & 1.48 years \\
\hline $18-35$ years & 31.3 & & \\
\hline $36-65$ years & 49.4 & & \\
\hline 66-93 years & 19.3 & & \\
\hline \multicolumn{4}{|l|}{ Socioeconomic Status } \\
\hline Non-manual, $n=5367$ & 51.6 & - & - \\
\hline Manual, $n=5034$ & 48.4 & - & - \\
\hline \multicolumn{4}{|l|}{ Ethnicity } \\
\hline White, $n=9764$ & 93.9 & - & - \\
\hline Black, Asian and Minority Ethnic/Prefer not to say, $n=637$ & 6.1 & - & - \\
\hline \multicolumn{4}{|l|}{ Personal Hearing Difficulty } \\
\hline Yes, $n=2510$ & 24.1 & & \\
\hline No, $n=7891$ & 75.9 & & \\
\hline \multicolumn{4}{|l|}{ Family Hearing Difficulty } \\
\hline Yes, $n=3390$ & 32.6 & & \\
\hline No, $n=7011$ & 67.4 & & \\
\hline Genetic Causal Beliefs $(1=$ not at all; $4=a$ lot $)$ & & 2.43 & 0.96 \\
\hline Behavioral Causal Beliefs $(1=$ not at all; $4=a$ lot $)$ & & 1.70 & 0.83 \\
\hline Extent of Recreational Noise Exposure in the Last 12 Months (Median = "Once every couple of months") & & 2.90 & 1.70 \\
\hline Hearing Protection Use (Median $=20 \%$ of occasions exposed) & & 1.90 & 2.25 \\
\hline
\end{tabular}

Note. Values that do not add up to $N=10,401$ indicate that participants 'preferred not to say' 


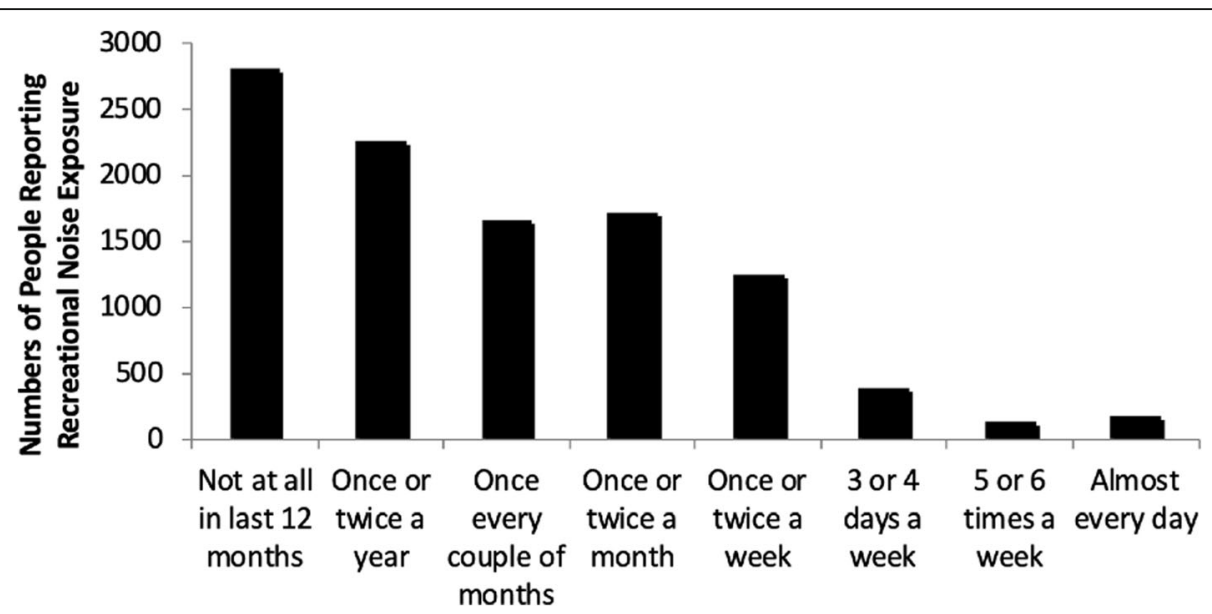

Fig. 1 Frequency of Recreational Noise Exposure

\section{Recreational noise exposure}

The majority of participants were exposed to recreational noise on only an occasional basis: $64.7 \%(n=$ 6732 ) reported experiencing recreational noise less than once a month (Fig. 1). Nevertheless a significant minority $(18.8 \%, n=1951)$ reported exposure to excessive recreational noise on at least a weekly basis. Multiple regression (Table 2) showed that men, younger people, people with a Black, Asian or Minority Ethnic background and those with personal experience of hearing loss were more likely to have been exposed to excessive recreational noise in the previous 12 months. Exposure was also associated with weaker beliefs in a genetic cause of hearing loss, stronger beliefs in a behavioral cause of hearing loss and greater use of hearing protection.

\section{Hearing protection use}

More than 7000 people $(n=7590,73.0 \%)$ reported some exposure to recreational noise in the last 12 months. Of those participants reporting some recreational noise exposure, $n=6007$ (79.2\%) reported zero use of hearing protection during noisy recreational activities in the last 12 months (Fig. 2); just 158 people (2.1\%) reported wearing hearing protection for every noisy recreational activity. The subsequent analyses focus on the 7590 participants who reported some exposure and hearing protection use was dichotomized into "no use" versus "some use" in the last 12 months.

Univariate and multivariate logistic regression was used to identify correlates of hearing protection use (Table 3). Four significant predictors emerged from both the univariate and the multivariate analyses. Men, younger people, stronger beliefs in a behavioral cause of hearing loss and greater exposure were all associated with greater hearing protection use.

\section{Discussion}

This study is the first of its kind to examine the extent of recreational noise exposure in the UK and associated hearing protection use. The key findings are that $73.0 \%$ of people reported exposure to recreational noise in the last 12 months and that hearing protection use is very

Table 2 Predictors of Recreational Noise Exposure

\begin{tabular}{|c|c|c|c|}
\hline Independent Variables & $B$ & SE & $95 \% \mathrm{Cl}$ \\
\hline Gender $($ men $=1$; women $=2$ ) & -.31 & .03 & $-.38,-.25^{*}$ \\
\hline Age & -.01 & .01 & $-.02,-.01^{*}$ \\
\hline Socioeconomic Status ( 1 = non-manual; 2 = manual) & .04 & .03 & $-.03, .10$ \\
\hline Ethnicity ( 1 = White; 2 = Black, Asian and Minority Ethnic/Prefer not to say) & .28 & .07 & $.14, .42^{*}$ \\
\hline Personal Hearing Difficulty & .29 & .04 & $.21, .37^{*}$ \\
\hline Family Hearing Difficulty & .10 & .04 & $.03, .17^{*}$ \\
\hline Genetic Causal Beliefs & -.04 & .02 & $-.08,-.01^{*}$ \\
\hline Behavioral Causal Beliefs & .08 & .02 & $.04, .12^{*}$ \\
\hline Hearing Protection Use & .33 & .04 & $.25, .41^{*}$ \\
\hline
\end{tabular}

Note. Greater exposure is associated with being a man, being younger, being from a Black, Asian and Minority Ethnic Background, experiencing personal hearing difficulty, having a family history of hearing difficulty, weaker genetic causal beliefs, stronger behavioral causal beliefs and greater hearing protection use ${ }^{*} p<.05$ 


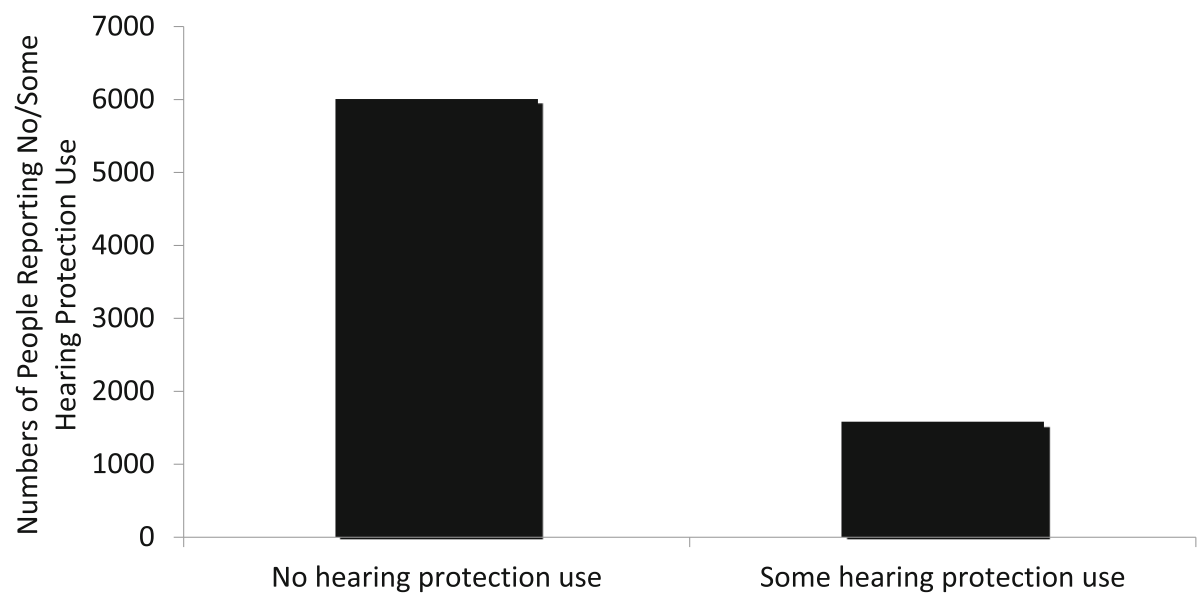

Fig. 2 Use of Hearing Protection Among People Exposed to Recreational Noise

low with $2.1 \%$ reporting wearing hearing protection for every noisy recreational activity. Experience of hearing loss is associated with greater exposure to recreational noise but not greater use of hearing protection. The following discussion considers the practical and policy implications of this work.

The present study highlights a substantial gap, among a representative sample of UK adults, between the extent of exposure to recreational noise and use of hearing protection that is similar to the rates found in students in the US [7] and Belgium [15]. The implication is that there is still much work to be done in raising awareness of recreational noise exposure and in promoting hearing protection use.

The present study sheds some light on the kinds of populations that may need to be targeted and the kinds of beliefs that might need to be changed to prevent recreational noise exposure and/or promote

Table 3 Predictors of Hearing Protection Use

\begin{tabular}{|c|c|c|c|}
\hline Independent Variables & $n(\%)$ Hearing Protection Users & OR $(95 \% \mathrm{Cl})$ & Adjusted OR $(95 \% \mathrm{Cl})$ \\
\hline Gender & & $0.57(0.51,0.64)^{*}$ & $0.60(0.54,0.68)^{*}$ \\
\hline Men & $938(25.4)$ & & \\
\hline Women & $623(16.2)$ & & \\
\hline Age & & $0.99(0.98,0.99)$ & $0.99(0.99,0.99)^{*}$ \\
\hline Socioeconomic Status & & $0.97(0.86,1.08)$ & $1.00(0.89,1.12)$ \\
\hline Non-manual & $899(21.1)$ & & \\
\hline Manual & $683(20.5)$ & & \\
\hline Ethnicity & & $1.49(1.20,1.84)$ & $1.24(0.99,1.55)$ \\
\hline White & $1457(20.4)$ & & \\
\hline Black, Asian and Minority Ethnic/Prefer not to say & $126(27.7)$ & & \\
\hline Personal Hearing Difficulty & & $0.99(0.87,1.13)$ & $1.06(0.92,1.22)$ \\
\hline Yes & $383(20.8)$ & & \\
\hline No & $1199(20.9)$ & & \\
\hline Family Hearing Difficulty & & $0.99(0.88,1.11)$ & $1.09(0.96,1.23)$ \\
\hline Yes & $529(20.7)$ & & \\
\hline No & $1053(20.9)$ & & \\
\hline Genetic Causal Beliefs & & $1.06(1.00,1.12)$ & $0.98(0.92,1.04)$ \\
\hline Behavioral Causal Beliefs & & $1.34(1.25,1.43)^{*}$ & $1.27(1.19,1.37)^{*}$ \\
\hline Extent of Exposure & & $1.22(1.17,1.26)^{*}$ & $1.16(1.12,1.21)^{*}$ \\
\hline
\end{tabular}

Note. Adjusted analyses include all predictors in the model. Greater hearing protection use is associated with being a man, being younger, having stronger behavioral causal beliefs and having greater exposure to recreational noise ${ }^{*} p<.05$ 
increase hearing protection use. The key findings were that: (a) interventions to reduce exposure might best be targeted at men and younger people, and that more needs to be done in terms of explaining that there is a behavioral underpinning to hearing loss; and (b) interventions to increase hearing protection use might best be targeted at women and older people with challenges made to the belief that hearing loss has a genetic cause.

Ensuring that people are aware of the behavioral underpinnings to hearing loss is something that could be implemented at a population level, rather than targeting specific groups and it is notable that exposure was associated with greater reported hearing loss. The implication is that perhaps exposure drives the belief that hearing loss has a behavioral as opposed to genetic cause of hearing loss, which chimes with research conducted in the US showing that the presence of hearing symptoms contributed to greater negative attitudes towards noise [7]. The implication is that early interventions to ensure that people are aware of behavioral causes of hearing loss prior to exposure are required.

\section{Strengths and limitations}

Although the present research takes the literature on the prevalence of recreational noise exposure and health protection use forward in some important respects, it is important to note some potential limitations. First, although the sample was large and representative, the cross-sectional design of the study means that causality cannot be inferred. Second, the nature of the research meant that exposure and use of hearing protection were self-reported, rather than assessed objectively. It would be valuable in future research to harness the power of new technology to gauge population exposure to recreational noise and use of hearing protection unobtrusively with a greater level of accuracy. Third, it is worth highlighting that, as a function of our interest in both recreational noise exposure and hearing protection use, our definition of noisy recreational activities excludes headphone and earphone use. This means that our estimate of exposure is likely to be lower than what has traditionally been considered to be total recreational noise exposure (i.e., including headphone and earphone use).

\section{Conclusions}

In sum, a significant proportion of the UK population are exposed annually to recreational noise, yet few take protective action. Younger people and men might be appropriate target groups to reduce exposure; whereas older people and women might be targeted with interventions to increase hearing protection use. However, a population-level approach to improving hearing health might usefully focus on ensuring that people have greater awareness of the behavioral causes of hearing loss.

\section{Supplementary information}

Supplementary information accompanies this paper at https://doi.org/10. 1186/s12889-020-09602-8.

\section{Additional file 1.}

Acknowledgements

We would like to thank Cath Wright and Kate Gosschalk for their help with approvals and data collection.

\section{Authors' contributions}

CJA, MTL and KJM contributed to the planning of the study. The analysis was conducted by CJA. The initial draft of the article was written by CJA. CJA, MTL and KJM revised the manuscript, and read and approved the final version for publication. CJA is the guarantor.

\section{Funding}

The study was funded by the NIHR Manchester Biomedical Research Centre and supported by the NIHR Greater Manchester Patient Safety Translational Research Centre. The funders had no role in the design of the study and collection, analysis, and interpretation of data and in writing the manuscript. The views expressed in this publication are those of the authors and not necessarily those of NIHR.

Availability of data and materials

The dataset used during the current study are available from the corresponding author on reasonable request.

Ethics approval and consent to participate

Ethical approval was obtained from a University of Manchester ethics committee (ref: 2019-5769-9246) and participants gave written informed consent at the beginning of the survey.

\section{Consent for publication}

N/A

\section{Competing interests}

None.

\section{Author details}

${ }^{1}$ Manchester Centre for Health Psychology, School of Health Sciences, University of Manchester, Manchester M13 9PL, UK. ${ }^{2}$ Manchester University NHS Foundation Trust, Manchester Academic Health Science Centre, Manchester M13 9PL, UK. ${ }^{3}$ Manchester Centre for Audiology and Deafness, School of Health Sciences, University of Manchester, Manchester M13 9PL, UK.

Received: 5 December 2019 Accepted: 23 September 2020 Published online: 09 October 2020

\section{References}

1. World Health Organization. (2015). Hearing loss due to recreational exposure to loud sounds: A review. Retrieved from: https://apps.who.int/iris/ handle/10665/154589.

2. Serra MR, Biassoni EC, Richter U, Minoldo G, Franco G, Abraham S, Carignani JA, Joekes S, Yacci MR. Recreational noise exposure and its effects on the hearing of adolescents. Part I: an interdisciplinary long-term study. Int J Audiol. 2005;44:65-73. https://doi.org/10.1080/14992020400030010.

3. Dehnert K, Raab U, Perez-Alvarez C, Steffens T, Bolte G, Fromme H, Twardella D. Total leisure noise exposure and its association with hearing loss among adolescents. Int J Audiol. 2015;54:665-73. https://doi.org/10. 3109/14992027.2015.1030510.

4. Gopal K. Current practices in the assessment of recreational noise-induced hearing loss: a review. Geneva: World Health Organization; 2017. 
5. Guest H, Dewey RS, Plack CJ, Couth S, Prendergast G, Bakay W, Hall DA. The noise exposure structured interview (NESI): an instrument for the comprehensive estimation of lifetime noise exposure. Trends Hear. 2018;22: Article no.: 2331216518803213. https://doi.org/10.1177/2331216518803213.

6. Washnik NJ, Phillips SL, Teglas S. Student's music exposure: Full-day personal dose measurements. Noise Health. 2016;18:98-103. https://doi.org/ 10.4103/1463-1741.178510

7. Balanay JAG, Kearney GD. Attitudes toward noise, perceived hearing symptoms, and reported use of hearing protection among college students: Influence of youth culture. Noise Health. 2015;17:394-405. https://doi.org/10. 4103/1463-1741.169701.

8. Beach E, Williams W, Gilliver M. Estimating young Australian adults' risk of hearing damage from selected leisure activities. Ear Hear. 2013;34:75-82. https://doi.org/10.1097/AUD.0b013e318262ac6c.

9. Jokitulppo JS, Björki EA, Akaan-Penttiä E. Estimated leisure noise exposure and hearing symptoms in Finnish teenagers. Scand Audiol. 1997;26:257-62. https://doi.org/10.3109/01050399709048017.

10. Jokitulppo J, Toivonen M, Bjoörk E. Estimated leisure-time noise exposure, hearing thresholds, and hearing symptoms of Finnish conscripts. Mil Med. 2006;171:112-6. https://doi.org/10.7205/MILMED.171.2.112.

11. Keppler H, Dhooge I, Vinck B. Hearing in young adults. Part II: the effects of recreational noise exposure. Noise Health. 2015;17:245-52. https://doi.org/ 10.4103/1463-1741.165026

12. Widén SE, Holmes AE, Erlandsson SI. Reported hearing protection use in young adults from Sweden and the USA: effects of attitude and gender: Reportes de uso de protección auditiva en jóvenes adultos en Suecia y en los EUA: Efectos de actitud y de género. Int J Audiol. 2006;45:273. https:// doi.org/10.1080/14992020500485676.

13. Zocoli AMF, Morata TC, Marques JM, Corteletti LJ. Brazilian young adults and noise: attitudes, habits, and audiological characteristics. Int J Audiol. 2009:48:692-9. https://doi.org/10.1080/14992020902971331.

14. Degeest $\mathrm{S}$, Clays $\mathrm{E}$, Corthals $\mathrm{P}$, Keppler H. Epidemiology and risk factors for leisure noise-induced hearing damage in Flemish young adults. Noise Health. 2017;19:10-9. https://doi.org/10.4103/1463-1741.199241.

15. Gilles A, Van Hal G, De Ridder D, Wouters K, Van de Heyning P. Epidemiology of noise-induced tinnitus and the attitudes and beliefs towards noise and hearing protection in adolescents. PLoS One. 2013; 8(Issue):7. https://doi.org/10.1371/journal.pone.0070297.

16. Jokitulppo J, Bjork E. Estimated leisure-time noise exposure and hearing symptoms in a Finnish urban adult population. Noise Health. 2002;5:53-62 http://www.noiseandhealth.org/text.asp?2002/5/17/53/31834.

17. Smith PA, Davis A, Ferguson M, Lutman ME. The prevalence and type of social noise exposure in young adults in England. Noise Health. 2000;2:4156 http://www.noiseandhealth.org/text.asp?2000/2/6/41/32650.

18. Gilliver $M$, Beach EF, Williams W. Changing beliefs about leisure noise: using health promotion models to investigate young people's engagement with, and attitudes towards, hearing health. Int J Audiol. 2015;54:211-9. https:// doi.org/10.3109/14992027.2014.978905.

19. Nguyen AB, Oh A, Moser RP, Patrick H. Perceptions of the roles of behaviour and genetics in disease risk: are they associated with behaviour change attempts? Psychol Health. 2015;30:336-53. https://doi.org/10.1080/08870446 2014.972958.

20. Benova L, Grundy E, Ploubidis GB. Socioeconomic position and healthseeking behavior for hearing loss among older adults in England. J Gerontol B Psychol Sci Soc Sci. 2014;70:443-52. https://doi.org/10.1093/geronb/ gbu024.

21. Lutman ME, Davis AC, Ferguson MA. Epidemiological evidence for the effectiveness of the noise at work regulations, Research Report. 2008:RR669 Retrieved from: https://www.hse.gov.uk/research/rrpdf/rr669.pdf.

\section{Publisher's Note}

Springer Nature remains neutral with regard to jurisdictional claims in published maps and institutional affiliations.

Ready to submit your research? Choose BMC and benefit from:

- fast, convenient online submission

- thorough peer review by experienced researchers in your field

- rapid publication on acceptance

- support for research data, including large and complex data types

- gold Open Access which fosters wider collaboration and increased citations

- maximum visibility for your research: over $100 \mathrm{M}$ website views per year

At $\mathrm{BMC}$, research is always in progress.

Learn more biomedcentral.com/submissions 